\title{
Proper metaphase spindle length is determined by centromere proteins Mis12 and Mis6 required for faithful chromosome segregation
}

\author{
Gohta Goshima, ${ }^{1}$ Shigeaki Saitoh, ${ }^{2}$ and Mitsuhiro Yanagida ${ }^{1-3}$ \\ ${ }^{1}$ Core Research for Evolutional Science and Technology (CREST) Research Project, Department of Biophysics, Graduate \\ School of Science, and ${ }^{2}$ Department of Gene Mechanisms, Graduate School of Biostudies, Kyoto University, \\ Kitashirakawa-Oiwakecho, Sakyo-ku, Kyoto 606-8502 Japan
}

\begin{abstract}
High-fidelity chromosome transmission is fundamental in controlling the quality of the cell division cycle. The spindle pole-to-pole distance remains constant from metaphase to anaphase A. We show that fission yeast sister centromere-connecting proteins, Mis6 and Mis12, are required for correct spindle morphogenesis, determining metaphase spindle length. Thirty-five to sixty percent extension of metaphase spindle length takes place in mis 6 and mis12 mutants. This may be due to incorrect spindle morphogenesis containing impaired sister centromeres or force unbalance between pulling by the linked sister kinetochores and kinetochore-independent pushing. The mutant spindle fully extends in anaphase, although it is accompanied by drastic missegregation by aberrant sister centromere separation. Hence, metaphase spindle length may be crucial for segregation fidelity. Suppressors of mis12 partly restore normal metaphase spindle length. In mis 4 that is defective in sister chromatid cohesion, metaphase spindle length is also long, but anaphase spindle extension is blocked, probably due to the activated spindle checkpoint. Extensive missegregation is caused in mis12 only when Mis12 is inactivated from the previous $M$ through to the following $M$, an effective way to avoid missegregation in the cell cycle. Mis12 has conserved homologs in budding yeast and filamentous fungi.
\end{abstract}

[Key Words: Cell cycle control; checkpoint; fission yeast; kinetochore; chromosome segregation; sister chromatid cohesion]

Received March 22, 1999; revised version accepted May 14, 1999.

The centromere is a specialized chromosomal DNA segment that serves as the site for protein-DNA and protein-protein interactions to form the kinetochore structure and ensures high-fidelity chromosome segregation in mitosis and meiosis (see e.g., Karpen and Allshire 1997; Saitoh et al. 1997; Clarke 1998; Moore et al. 1998; Williams et al. 1998). The smallest centromere is that of the budding yeast Saccharomyces cerevisiae, which has been the subject of extensive studies to identify individual components necessary for proper centromere functions (for example, see Espelin et al. 1997; Meluh et al. 1998). Similar studies have been done on different organisms with larger centromeres such as the fission yeast Schizosaccharomyces pombe, Drosophila, and mammals (see e.g., Chen et al. 1996; Ekwall et al. 1997; Sun et al. 1997; Csink and Henikoff 1998; Ikeno et al. 1998; Willard 1998). However, little is understood of how faithful chromosome segregation is accomplished in mitotic cells. During replication, the centromere se-

${ }^{3}$ Corresponding author.

E-MAIL yanagida@kozo.biophys.kyoto-u.ac.jp; FAX 81757534208. quence is duplicated, forming sister centromeres that are held together tightly. Kinetochore microtubules are associated with the kinetochores at one end and with the spindle poles at the other end during mitosis, and exert a pulling force on the sister chromatids to bring them toward the opposite poles (see e.g., Rieder and Salmon 1998). The loss of sister chromatid cohesion (Miyazaki and Orr-Weaver 1994) might be a positive factor in driving sister chromatid separation, and concerted separation of multiple chromosomes may be accomplished by cooperative pulling and dissociation of sister chromatids.

How is the onset of anaphase initiated? Ubiquitin-mediated and destruction box (DB)-dependent Cut2 proteolysis is necessary to initiate anaphase in fission yeast (Funabiki et al. 1996a); Pds1 is a counterpart in budding yeast (Cohen-Fix et al. 1996; Yamamoto et al. 1996). These are collectively called securin (Nasmyth 1999). Cut2 appears to inhibit Cut1 (Esp1 in budding yeast, and a gene family name of separin) by direct association, and Cut2/Pds1/securin proteolysis may activate Cut1/Esp1/ separin (Funabiki et al. 1996b; Ciosk et al. 1998; Kumada 
et al. 1998; Nasmyth 1999). For polyubiquitination, the anaphase-promoting complex (APC)/cyclosome, which is essential for polyubiquitination of mitotic cyclin and Cut2, must be activated (King et al. 1995; Sudakin et al. 1995; Yamano et al. 1996; Yamashita et al. 1996; Funabiki et al. 1997; Yamada et al. 1997; Kim et al. 1998). In fission yeast mutants defective in APC/cyclosome subunits (Hirano et al. 1988; Yanagida 1998) or in proteasome (Gordon et al. 1993), cells are arrested at a metaphase-like stage with the short spindle and highly condensed chromosomes. Cyclin and Cut2 remain without anaphase proteolysis in these mutants. The onset of anaphase is thus regulated by ubiquitin-mediated proteolysis and this is thought to ensure harmonious chromosome segregation.

At least three evolutionarily conserved groups of proteins are responsible for sister chromatid cohesion. Rad21/Mcd1p/Scc1p /Guacci et al. 1997; Michaelis et al. 1997; Losada et al. 1998; Uhlmann and Nasmyth 1998) forms the complex called cohesin with two other proteins (Smc1p and Smc3p) of the SMC family. The second type of chromatid cohesion molecule is Mis4/Scc2p, called adherin (Furuya et al. 1998). These become essential during the $S$ phase and appear to link two sister chromatids together until anaphase. The third is Ctf7p/ Ecolp, which is required for the establishment of cohesion during DNA replication (Skibbens et al. 1999; Toth et al. 1999). The loss of these cohesion molecules apparently leads to the failure to hold sister chromatids after replication, and therefore sister chromatids are prematurely separated. Esp1p was shown to be essential for the removal of Scclp from sister chromatids in anaphase (Ciosk et al. 1998), but similar events have not been found in fission yeast (T. Nakamura, K. Kumada, and M. Yanagida, unpubl.). Cut1 protein appeared to be needed for activating the anaphase spindle on Cut2 proteolysis (Kumada et al. 1998); loading of Cut1 onto the anaphase spindle required the carboxy-terminal-conserved amino acids.

More restricted sister chromatid linking has been reported for fission yeast Mis6, which is required to connect the sister centromeres in metaphase-arrested cells (Saitoh et al. 1997). Whereas sister chromatid cohesion molecules such as $\operatorname{Rad} 21$ and Mis4 locate along the entire length of chromatids, Mis6 tagged with GFP is visualized only at centromeres. Fission yeast centromeres are large and complex (see e.g., Takahashi et al. 1992), and Mis6 is shown to associate with the inner regions essential for precise segregation. In temperature-sensitive mis6-302 cultured at the restrictive temperature $\left(36^{\circ} \mathrm{C}\right)$, sister chromatids are separated but radically missegregated (Takahashi et al. 1994). Mis6 is necessary to construct specialized chromatin present in the inner centromeres; smeared nucleosome ladders obtained by the inner centromere DNA probes were abolished in mis6 mutant (Saitoh et al. 1997). Drastic missegregation phenotype in anaphase is produced only after cells proceed across from $\mathrm{G}_{1} / \mathrm{S}$ to $\mathrm{M}$ at $36^{\circ} \mathrm{C}$. Mis6 normally acts during $G_{1}$ or at the onset of $S$ phase but may be functionally restored at a later stage. If mis6 mutant cells are cultured at $36^{\circ} \mathrm{C}$ from $\mathrm{G}_{1}$ and then arrested at metaphase, sister centromeres are already separated, but other parts of chromatids are associated, suggesting that Mis6 is involved in linking sister centromeres. If, however, the sister cohesion protein Mis4 is inactivated, the entire length of chromatids including centromeres are prematurely separated in the presence of Mis6 (Furuya et al. 1998). Mis4 is independently needed for sister centromere connection.

In fission yeast, behavior of centromeric DNA during mitosis has been visualized in living cells with GFPLacI-NLS, which can bind to the LacO repeats integrated near the cen 1 (Nabeshima et al. 1998). Combined with the images obtained by GFP-Sad1, a GFP-tagged spindle pole body (SPB) protein, spindle, and centromere dynamics in mitosis in the wild-type cells are now fairly well understood. Spindle dynamics in $S$. pombe consists of three phases: Phase 1 is the duration of spindle formation, whereas in phase 2, the spindle has a constant length. Sister chromatid separation occurs at the end of phase 2. Phase 2 consisting of the stages similar to metaphase and anaphase A in higher eukaryotes is crucial for understanding the onset of anaphase. Spindle elongation (similar to anaphase B) occurs in phase 3 . The durations of phases 1,2 , and 3 are, respectively, $2.5,7.0$, and $15 \mathrm{~min}$ at $26^{\circ} \mathrm{C}$ and $1.4,4.0$, and $6.2 \mathrm{~min}$ at $36^{\circ} \mathrm{C}$.

Among 12 mis (minichromosome instability) genetic loci identified (Takahashi et al. 1994), only 3, mis4, mis6, and mis12, gave rise to the missegregation phenotype of regular chromosomes at $36^{\circ} \mathrm{C}$. We were interested in how regular chromosomes in mis12-537 mutant cells were missegregated and undertook to characterize the phenotypes of mis12-537 and identify the gene product. Mis12 plays a unique role in regulating the functional centromeres during the cell cycle.

\section{Results}

Expansion of the metaphase spindle in mis12-537

To determine whether spindle formation and elongation was normal in the mis12-537 mutant, the gene for Sad1GFP, the SPB protein (Hagan and Yanagida 1995) tagged with GFP (Nabeshima et al. 1998), was expressed by multicopy plasmid in wild-type and mis12-537 at $36^{\circ} \mathrm{C}$. Time-lapse images of living cells in the culture medium at $36^{\circ} \mathrm{C}$ (images taken after $3.5-8 \mathrm{hr}$ because the phenotype was produced in the second mitosis, see below) were taken at 30-sec intervals by a confocal microscope (Nabeshima et al. 1997). The elevated dosage of Sad1GFP results in extra localization at the nuclear envelope, a convenient marker for the shape of the nucleus. More than 20 living mis12 cells and 6 wild-type cells were observed. Two living mis12 cells and one wild-type control cell are shown, respectively, in Figure 1, A and B (the number indicates minutes). The spindle is fully extended in the mutant, although daughter nuclei produced are unequal in size (see nuclear images at 16.5 and $10.5 \mathrm{~min}$ ).

Another striking anomaly was discovered in mutant cells with regard to spindle length of phase 2 , the period corresponding to metaphase to anaphase $\mathrm{A}$ in higher eu- 
Goshima et al.

Figure 1. The metaphase spindle is expanded in mis12. (A) Two living mis12537 cells expressing Sad1-GFP cultured at $36^{\circ} \mathrm{C}$ for $7-8 \mathrm{hr}$ and observed at $0.5 \mathrm{~min}$ intervals by a confocal microscope. The number indicates minutes. Asymmetric nuclear division is evident for both cells. Bar, $10 \mu \mathrm{m}$. (B) A wild-type control. $(C)$ Time-course of the pole-to-pole distance measured for three mis12 (\#1-\#3) and one wild-type (WT) cell. Three phases are clearly distinguished (see text). (D) The pole-to-pole distances in the spindle of phase 2 measured for 22 mis12 (solid bars) and 6 wild-type cells (open bar) are plotted. Frequencies are expressed as the number of living cells for which mitosis was analyzed. (E) Plot of duration of time for phase 2 measured for the same number of mis12 (shaded bars) and wild-type cells (open bars). (F) Two mis12 mutant cells cultured at $36^{\circ} \mathrm{C}$ for $5 \mathrm{hr}$ (left) and $8 \mathrm{hr}$ (right) and expressing the cen1-GFP. The number indicates minutes.
A
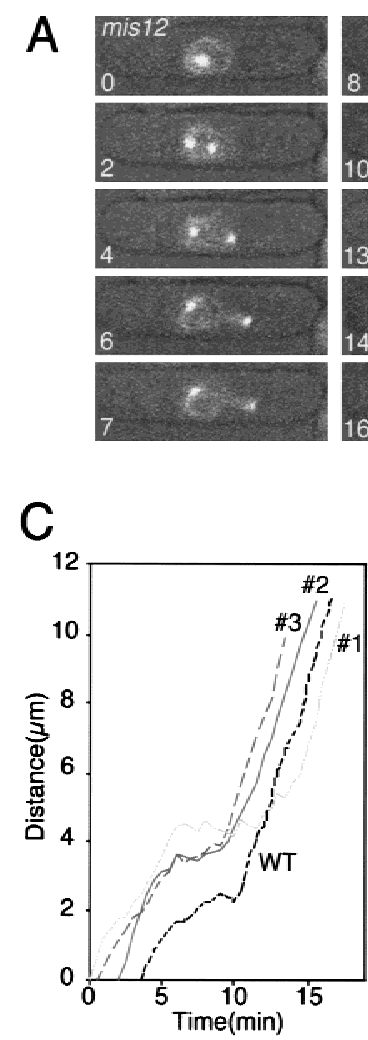
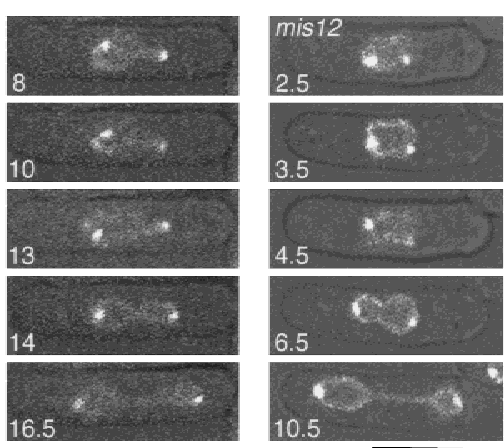

B
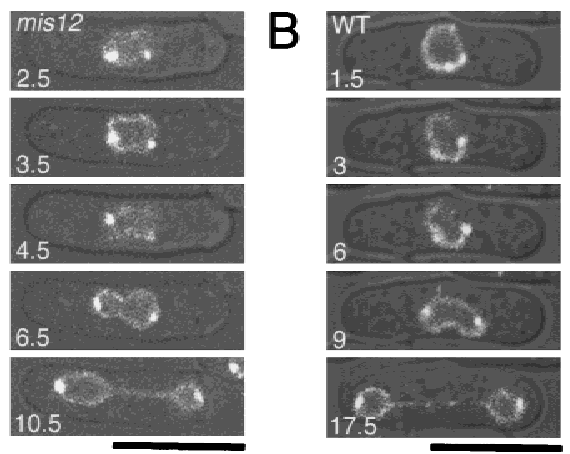

D

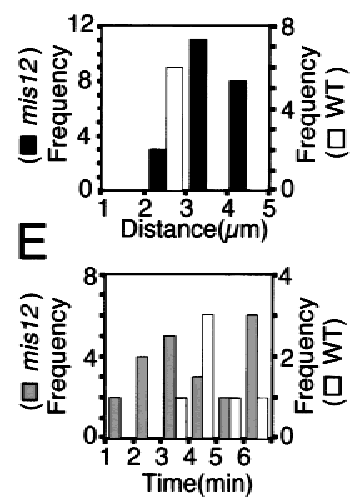

$\mathrm{F}$
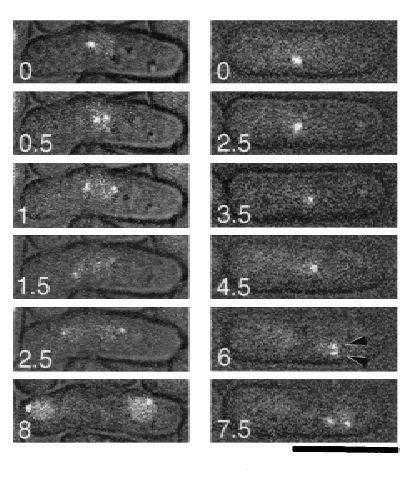

karyotes. Phase 2 is crucially important for understanding mitosis as the duration and length of the phase-2 spindle appears to be precisely regulated (Nabeshima et al. 1998). Centromeres move quickly back and forth along the spindle in phase 2 . Time course of the pole-topole distance (defining spindle length) for three mis12 sample cells (\#1-3, Fig. 1C) demonstrates that the three phases of spindle dynamics clearly exist in mis12, but the spindle in phase 2 is much longer than that of wild type. In Figure 1D, the data for all mis12 cells examined are shown: the average pole-to-pole distance $(3.7 \pm 0.7$ $\mu \mathrm{m}$ ) is $60 \%$ longer in mis 12 (solid columns) than that of wild type (open column, $2.3 \pm 0.2 \mu \mathrm{m})$. Pear-shaped $(6-10$ $\mathrm{min}$ in the left cell of Fig. 1A) or ellipsoidal (2.5-4.5 min in the right cell) nuclei were seen in mis12 cells during phase 2. One end of the spindle often protruded from the nuclear envelope, causing the pear-shaped nuclei. These extended nuclei were rarely observed in the wild-type phase 2 , in which length of the phase- 2 spindle was the same as the diameter of the spherical nucleus. We concluded from these results that Mis12 was required for correct spindle morphogenesis in metaphase.

The other phenotype aberrance in mis12 was that the duration of phase 2 was much more heterogenous in the mutant (average $5.4 \pm 4.2 \mathrm{~min}$ ) than the wild type $(4.3 \pm 0.9 \mathrm{~min})$ (Fig. 1E), indicating that the occurrence of the end of phase 2 could be premature or delayed. Under the permissive condition, however, these spindle phenotypes of mis12 were reversed to the normal ones (data not shown). As detailed in the results described later, the defective phenotype of mis12 was revealed in the second mitosis at $36^{\circ} \mathrm{C}$ and the first mitosis (images taken $0-3$ $\mathrm{hr}$ after the shift of asynchronous culture to $36^{\circ} \mathrm{C}$ ) produced normal, wild-type-like mitosis indistinguishable from that shown in Figure 1B (data not shown).

\section{Aberrant centromere separation in mis 12}

To gain more information about the phenotype of mis12, it was observed how the sister centromeres (cen) behaved during mitosis. For this procedure, the cen1-GFP probe used previously (Nabeshima et al. 1998) was applied to visualize cen DNA. Briefly, LacI-GFP was expressed in $S$. pombe cells integrated with the tandem $\mathrm{LacO}$ sequences near the cen1. LacI-GFP bound to the LacO site was an appropriate marker for the cen 1 DNA. As the cen1-GFP signal was very faint at $36^{\circ} \mathrm{C}$ compared with Sad1-GFP, simultaneous observation of cen1-GFP and Sad1-GFP at $36^{\circ} \mathrm{C}$ has not been successful (it was pos-

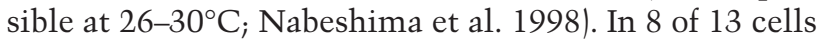
undergoing the second mitosis, the cen1-GFP signal was rapidly split in mis12 apparently as in wild type (Fig. 1F left, $0-1 \mathrm{~min})$. In other cases $(5 / 13)$, the centromere signal movement was abnormal. Four cells showed the movement of cen1-GFP to one direction without splitting, followed by separation (right, $6 \mathrm{~min}$ ), leading to two cen1-GFP signals in one divided nucleus (indicated by the arrowheads). As S. pombe cells contain three haploid chromosomes, aberrant centromere movement, if it occurred for each chromosome at the same frequency, could explain the lethality of mis12 cells by their production of aneuploidy cells (see Discussion). 


\section{Aberrant metaphase spindle size in the mis6 mutant}

A similar set of experiments was done with mis6-302. Fifteen mutant cells analyzed all revealed the three distinct spindle phases as in mis12. Time-lapse images of Sad1-GFP in one mis 6 cell at $36^{\circ} \mathrm{C}$ are shown in Figure 2A. Aberrant pear-shaped nuclear formation (seen at 9 min in A) followed by unequal nuclear division (at 13.5 min) is also seen in the mutant cells. Two mutant cells after 6.0 and $4.2 \mathrm{hr}$ at $36^{\circ} \mathrm{C}$ (\#1 and \#2, respectively) in Figure 2B (left) showed expansion of the phase-2 spindle. Average length of the phase-2 spindle in mis6 (3.1 \pm 0.5 um; Fig. 2B, right, solid columns) was $35 \%$ longer than that of wild type (open column, $2.3 \pm 0.2 \mu \mathrm{m})$. Mis 6 is thus also required for correct spindle morphogenesis at metaphase. The duration of phase $2(4.9 \pm 1.7 \mathrm{~min})$ in mis6 was more variable than the wild type. To further confirm that metaphase spindle length was extended in the mis 6 mutant, spindle length of metaphase-arrested cut9 mis 6 and cut9 cells was measured (cut9) is defective in polyubiquitination of mitotic cyclin and Cut2; Funabiki et al. 1996a). Single and double mutants were first arrested in $\mathrm{G}_{1}$ by nitrogen starvation and then released to the complete medium at $36^{\circ} \mathrm{C}$. After $8 \mathrm{hr}$, metaphase cells were accumulated because of the inactivation of Cut9 mutant protein. In metaphase-arrested cut9 mis6 double mutant, sister centromeres were prematurely dis-

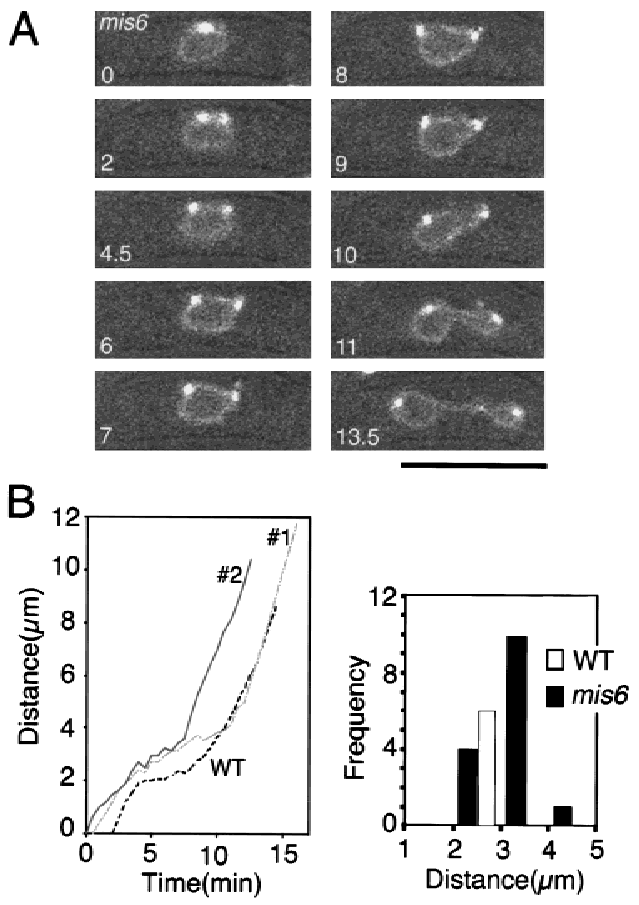

Figure 2. Expansion of the pole-to-pole distance in metaphase also occurs in the mis6 mutant. (A) One living mis6 mutant cell cultured at $36^{\circ} \mathrm{C}$ for $6 \mathrm{hr}$ and expressing Sad1-GFP is shown. The number indicates minutes. Phase 2 lasts from 6 to $10 \mathrm{~min}$. Bar, $10 \mu \mathrm{m}$. (B, left) Time course of the pole-to-pole distance in two mis6 mutant cells (\#1, \#2) and one wild-type cell (right). Distribution of length of the phase-2 spindle in 15 mis6 cells (solid bars) is shown with the wild-type control (open bar).
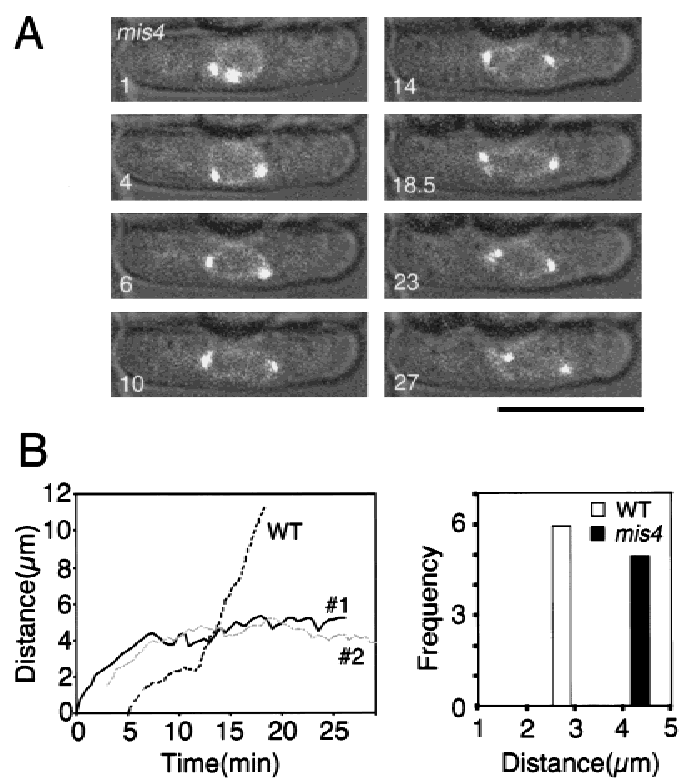

Figure 3. Impaired spindle elongation in mis4. (A) Time-lapse images of one mis4-242 cell expressing Sad1-GFP and cultured at $36^{\circ} \mathrm{C}$ for $4 \mathrm{hr}$. Bar, $10 \mu \mathrm{m}$. $(B$, left $)$ Time course of the poleto-pole distance in two mis 4 mutant cells $(\# 1, \# 2)$ at $36^{\circ} \mathrm{C}$. The spindle formed and increased in length without interruption up to 4-5 $\mu \mathrm{m}$, thereafter, the pole-to-pole distance increased very slowly. (Right) Distribution of the pole-to-pole distances measured for mis4 cells is shown (solid bar).

sociated because of the inactivation of the Mis6 mutant protein, but not in the single cut9 (Saitoh et al. 1997). At that time, the metaphase spindle length of cut9 mis6 was $25 \%$ longer than that of single cut9 mutant (data not shown).

\section{Spindle extension blocked in a sister chromatid cohesion mutant, mis4}

Spindle length in phase 2 was normal in top 2 and cut14 mutants at $36^{\circ} \mathrm{C}$ (Nabeshima et al. 1998), respectively, and both were defective in chromosome condensation and separation. In nuc2 and cut9 mutants blocked at metaphase because of the defects in anaphase promoting proteolysis (Yamada et al. 1997), spindle length was similar to that of wild-type metaphase cells. In contrast, spindle length in phase 2 was aberrant in mis4-242. The phase- 2 spindle formed in mis 4 was twice $(4.6 \pm 0.1 \mu \mathrm{m})$ the length of wild type, but it did not actually elongate further for a long period (Fig. 3A,B), whereas sister chromatid separation had already occurred (this was confirmed by FISH with the centromere probe, data not shown). The mutant spindle increased without interruption during phase 1 (Fig. 3A) and then remained in a phase 2-like stage for a long period (Fig. 3B, left). The length of the spindle in mis4 was surprisingly uniform (Fig. 3B, right). Restraining spindle elongation in mis4 might represent a mitotic checkpoint arrest due to pre- 
mature sister chromatid dissociation, because the mitotic spindle was further elongated in mis 4 when the spindle checkpoint protein mad2 was deleted (K. Furuya and $M$. Yanagida, unpubl.).

In metaphase-arrested cut9 mis 4 at $36^{\circ} \mathrm{C}$ (cells were initially nitrogen starved and then shifted to the complete medium at $36^{\circ} \mathrm{C}$ ), spindle length was $75 \%$ longer $3.7 \pm 0.8 \mu \mathrm{m}$ in fixed and anti-Sad 1 antibody-stained cells) than in single cut9 $(2.1 \pm 0.5 \mu \mathrm{m})$ at $36^{\circ} \mathrm{C}$ (data not shown).

\section{Mis12, a 30-kD protein locating at centromeres throughout the cell cycle}

The mis $12^{+}$gene was isolated by chromosome and cosmid mapping (Materials and Methods). The isolated gene rescued the temperature-sensitive phenotype of mis12537. The mis $12^{+}$gene encodes a novel protein containing 259 amino acids. Database search showed that S. cerevisiae, Aspergillus nidulans, and Magnaporthe grisea coding sequences (YAL034W-A, ENAC000133, and mgae0004dC05f, respectively) significantly resemble the predicted sequence of Mis12 (Fig. 4A). The S. cerevisiae gene product was designated Mtwlp (Mis twelve-like protein). Sequence similarity was confined in the 88 amino-terminal amino acids. Protein structure prediction with the program COILS indicates that the central regions of Mis12 (100-150) and Mtw1p (101-150) might be coiled-coil.

Gene disruption was performed by one-step replacement. Most of mis $12^{+}$was replaced by the S. pombe ura $^{+}$gene. Ura ${ }^{+}$heterozygous diploid cells obtained by homologous integration were dissected. Only two spores were viable, and both were $\mathrm{Ura}^{-}$, demonstrating that Mis12 was essential for cell viability. mis12 null cells divided two to four times after germination. They were observed after DAPI stain (Fig. 4B): The daughter nuclei with unequal sizes were highly frequent, showing that the temperature-sensitive and null phenotypes were similar.

To confirm that the Mis12 protein had the expected molecular weight, immunoblotting was performed. The HA (hemagglutinin antigen)-tagged Mis12 protein band with the expected molecular weight was detected in cell extracts carrying the integrated Mis12-HA gene by antiHA antibody (Fig. 4C, lane 2). The integrated HA-tagged Mis12 sedimented around 4-12S in sucrose gradient centrifugation, whereas Mis6 was broadly distributed, forming a peak at $15 \mathrm{~S}$ (data not shown); this suggested that Mis12 and Mis6 belonged to different molecular complexes although their localizations were similar (see below).

Intracellular localization of Mis12 was visualized by GFP tagging (the mis $12^{+}-\mathrm{GFP}$ gene integrated onto the chromosome with the native promoter for $\mathrm{A}$ and $\mathrm{D}$ or expressed in plasmid for B and C). The GFP signals were clustered into one dot at the SPBs in interphase (the top cell in Fig. 5A; the bottom cell in early mitosis), whereas two or three signals were seen along the spindle in mitosis (Fig. 5B), visualized by anti-tubulin staining (TUB). In mitotically-arrested nda3-311 ( $\beta$-tubulin) mutant, the single Mis12-GFP signal was seen on each of the hypercondensed chromosomes (Fig. 5C). These results showed that Mis 12 was localized at centromeres throughout the cell cycle.

The Mis12-GFP signals seen in living cells were consistent with those of fixed cells. Localization of Mis12GFP strongly resembled that of Mis6-GFP (Saitoh et al. 1997). The Mis12-GFP signal was clustered until late $G_{2}$ (0 min in Fig. 5D), and became multiple in $M(1 \mathrm{~min})$, often seen as two or three dots along the short rod (2-6 min) during the putative metaphase, and then rapidly separated (6.5-7 $\mathrm{min})$, followed by further separation in anaphase B. Mis12 appeared to be bound to the centromere of all the chromosomes.

Figure 4. Mis12 is an essential conserved protein. (A) Sequences of S. cerevisiae, A. nidulans, and $M$. grisea are similar to the amino terminus of Mis12. (Top) Identical amino acids are boxed; similar ones are shaded. (Bottom) Alignment of Mis12 and Mtwlp. The predicted coiled-coil exists in the middle (amino acids 100-150); while the conserved regions are in the amino terminus (amino acids 1-88). (B) Gene disruption of mis $12^{+}$led to the missegregation phenotype with the large and small daughter nuclei. Gene-disrupted cells were stained by DAPI. Bar, $10 \mu \mathrm{m}$. (C) Identification of Mis 12 protein by immunoblotting. The carboxyl terminus of the mis $12^{+}$gene was tagged with HA and integrated onto the chromosome of mis12-537 by homologous recombination (the promoter was native). The temperature-sensitive phenotype was rescued in

A

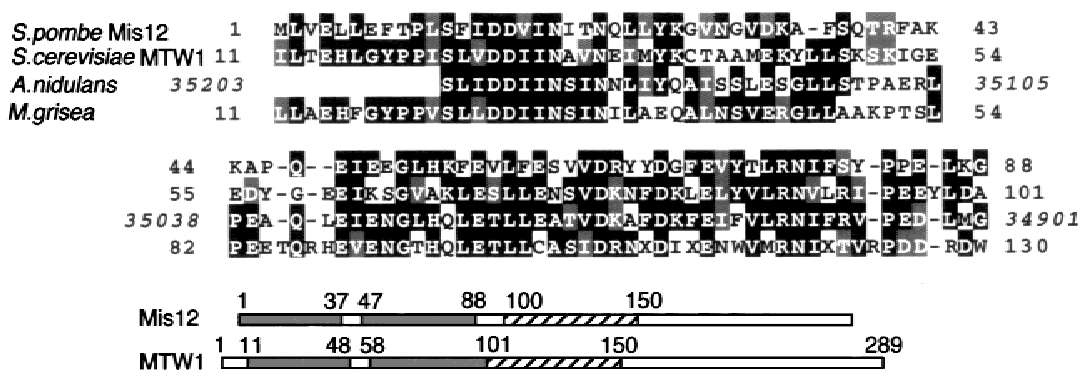

B

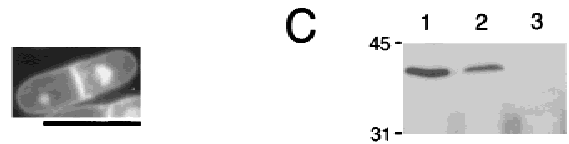

the resulting integrant, which grew normally. Mis12 was detected at the expected molecular mass (lane 2). The band intensity increased in cells overproducing Mis12-HA by multicopy plasmid (lane 1), but the band was not detected in extracts carrying the vector (lane 3). 

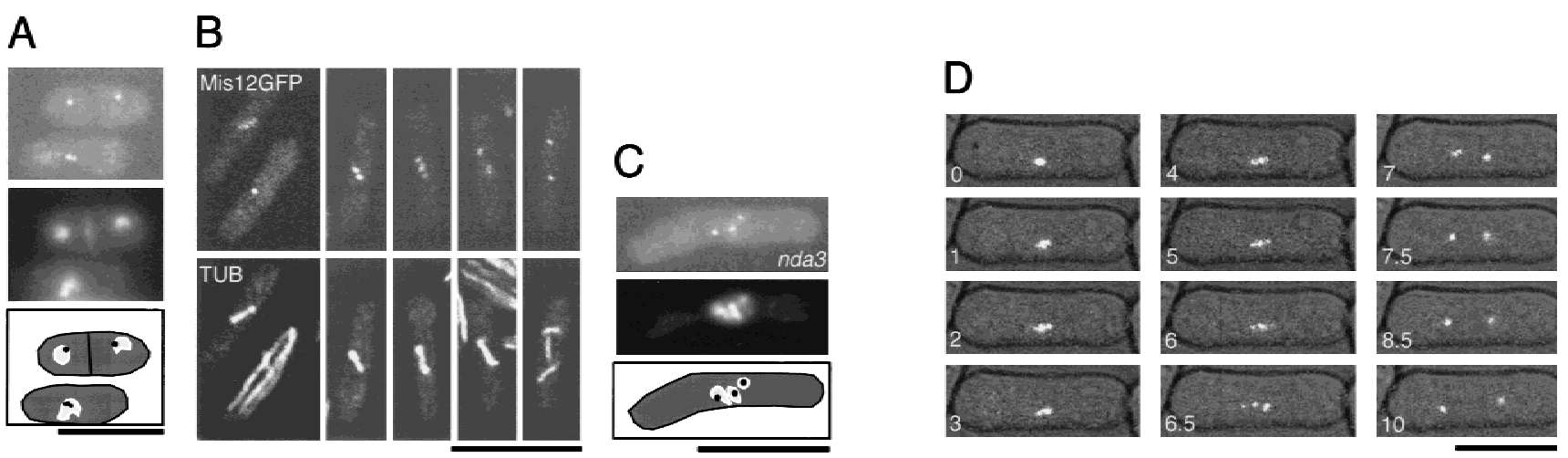

Figure 5. Mis12-GFP colocalizes with the centromeres. (A) Mis12-GFP was expressed by the single-copy-integrated gene and observed by fluorescence microscopy after Hoechst 33342 staining. The GFP signal was located as a dot on the periphery of the interphase nucleus (top). Hoechst 33342 stained (middle) and the merged images (bottom) are also shown. (B) Visualization of microtubules (TUB) and Mis12-GFP in methanol-fixed cells. Mis12-GFP expressed by multicopy plasmid with the native promoter was observed after cells were treated with methanol and stained with anti-tubulin antibodies. (C) Mis12-GFP (top) was expressed by multicopy plasmid in nda3-311 (defective in $\beta$-tubulin) cultured at $20^{\circ} \mathrm{C}$ for $8 \mathrm{hr}$. DAPI (middle) and the merged (bottom) images are also shown. (D) Time-lapse images of one living wild-type cell expressing Mis12-GFP by the single-copy integrated gene. The number indicates minutes. Bars, $10 \mu \mathrm{m}$.

\section{Requirement of Mis12 for maintaining inner centromere structure}

The chromatin immunoprecipitation method was used to identify the centromere DNA that interacts with Mis12. Four primers, imr1, cnt1, otr2 (dhII), and lys1 were used (Fig. 6A; Takahashi et al. 1992). Combination of Mis12-HA and anti-HA antibody produced the PCR products (lane 1), when the inner centromere primers cnt 1 and imrl were used, but not the outer region primers otr2 or lys1. Beads alone without antibody (lane 2) did not produce any PCR DNA. These results indicated that Mis12 interacted with the inner centromere DNAs.

As Mis6 was also shown to be an inner-centromereinteracting protein (Saitoh et al. 1997), we examined whether Mis12 formed the complex with Mis6. To this end, immunoprecipitation was done with HA-Mis12 and Myc-Mis6, both of which were expressed by the genes integrated onto the chromosome. Most of the Mis12-HA was precipitated (Ppt) by anti-HA antibodies, but no Mis6-Myc was detected in the precipitates (Fig. 6B). There was no cross-precipitation between Mis12HA and Mis6-Myc, showing that the Mis6 and Mis12 did not form the stable complex.

To answer the question whether the Mis 6 mutant protein could interact with the inner centromere, the mutant mis6-302 gene was tagged with HA and integrated onto the chromosome. Mis6-302-HA was immunoprecipitated after formaldehyde fixation. The levels of the PCR products were reduced at $26^{\circ} \mathrm{C}$ and negligible at $36^{\circ} \mathrm{C}$, indicating that the primary defect in mis6-302 was due to its deficient interaction with the centromeres (data not shown).

To determine whether association of Mis 6 to the inner centromere region required active Mis12, a mis12-537 strain expressing the integrated Mis6-HA was made, cultured at $36^{\circ} \mathrm{C}$ for $6 \mathrm{hr}$, and extracts were prepared and immunoprecipitated by anti-HA antibody (Fig. 6C).
Nearly identical amounts of cen-DNA were precipitated from the wild-type (lane 1) and mis12 mutant (lane 2). Lanes 4, 5, and 6 are loading control. Hence, mis6-HA could interact with the centromere in the absence of functional Mis12. Conversely, the mis6-302 strain integrated with the Mis12-HA gene was used. Immunoprecipitated Mis12-HA in mis6-302 was bound to the inner centromere regions (lane 8). Mis6 and Mis12 appeared to interact independently with the centromeres.

\section{Loss of centromere-specific chromatin digestion pattern in the mis12 mutant}

The inner centromere DNAs of $S$. pombe has a specialized chromatin (Polizzi and Clarke 1991; Takahashi et al. 1992). In the mis6-302 mutant, the smeared chromatin pattern is abolished at $36^{\circ} \mathrm{C}$ (Saitoh et al. 1997). The same result was obtained in mis $12-537$ at $36^{\circ} \mathrm{C}$ (Fig. 6D): The inner centromere probes for hybridization, cnt 1 and imrl, failed to show the smeared pattern in mis12 mutant cultured at $36^{\circ} \mathrm{C}$ for $8 \mathrm{hr}$ (the ethidium bromide staining pattern shown at the right end). The patterns for the wild-type control are also shown. Mis12 is thus required for maintaining the inner centromere structure.

\section{Missegregation occurs after the passage of mis 12 in the previous mitosis}

To understand the role of Mis12, it is important to determine how its action is implicated in the cell cycle. First, chromosome missegregation (unequal nuclear division seen by DAPI stain was verified to be missegregation by FISH; Fig. 7A) took place in mis12-537 cells after one cycle of cell division at $36^{\circ} \mathrm{C}$ (Fig. 7B). The phenotype did not appear for the first division (1-3 hr). The majority of cells of fission yeast in the asynchronous culture were in $G_{2}$. Eighty percent of the binucleate cells 
Figure 6. Requirement of Mis12 for maintaining the inner centromere. $(A, t o p)$ Organization of the cen 1 is schematized (Takahashi et al. 1992). Probes used for PCR primers and Southern hybridization are indicated by vertical and horizontal bars, respectively. (Bottom) Cells expressing the Mis12-HA by the integrated gene were immunoprecipitated after fixation with formaldehyde and glass bead breakage. Coprecipitated DNA was amplified by PCR with the primers of cnt1, imr1, otr2 (dh), and lys1 (Saitoh et al. 1997). These primer sequences (indicated by the vertical bars) were unique or repeated up to three times in the genome. Approximately the same level of PCR-made DNAs was obtained as control from the strain expressing Mis12-HA and the wild-type 972 (lanes 4,5). Precipitates of anti-HA yielded the PCR products of cnt 1 and imrl but not of otr2 or lys1 (lane 1). Lanes 2 and 3 are the control with beads alone or the wild-type 972 extract, respectively. (B) S. pombe cells expressing Mis12-HA and Mis6-Myc were immunoprecipitated by anti-HA antibody, and the materials precipitated (Ppt) and supernatant (Sup) were immunoblotted with anti-HA and anti-Myc antibodies. Mis6Myc was not present in the precipitates. $(C)$ mis12-537 mutant expressing the integrated Mis6-HA (lanes 2,5) and mis6-302 express-
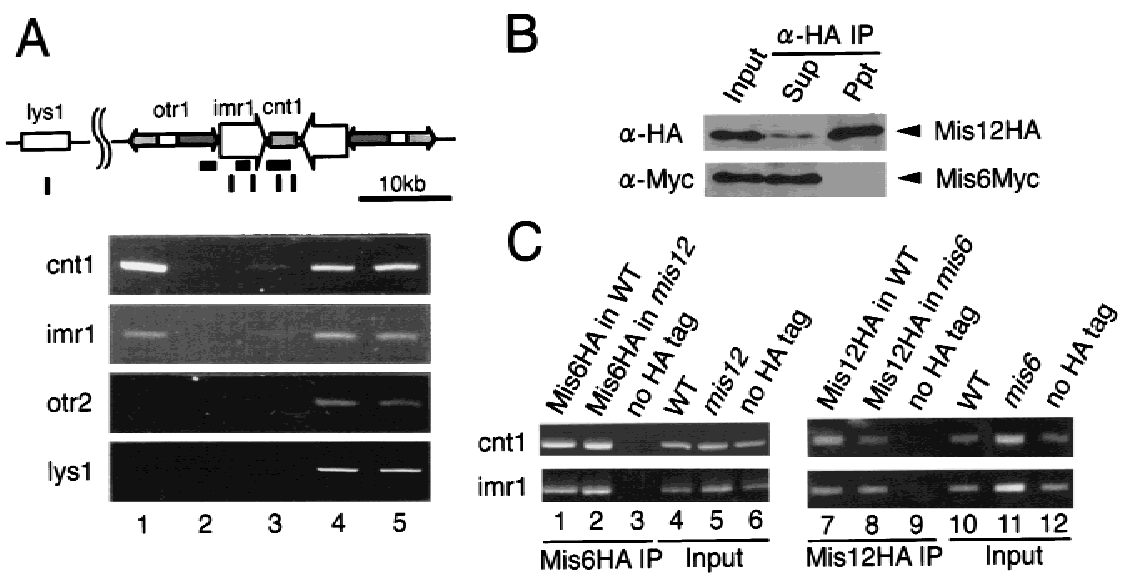

$\mathrm{D}$
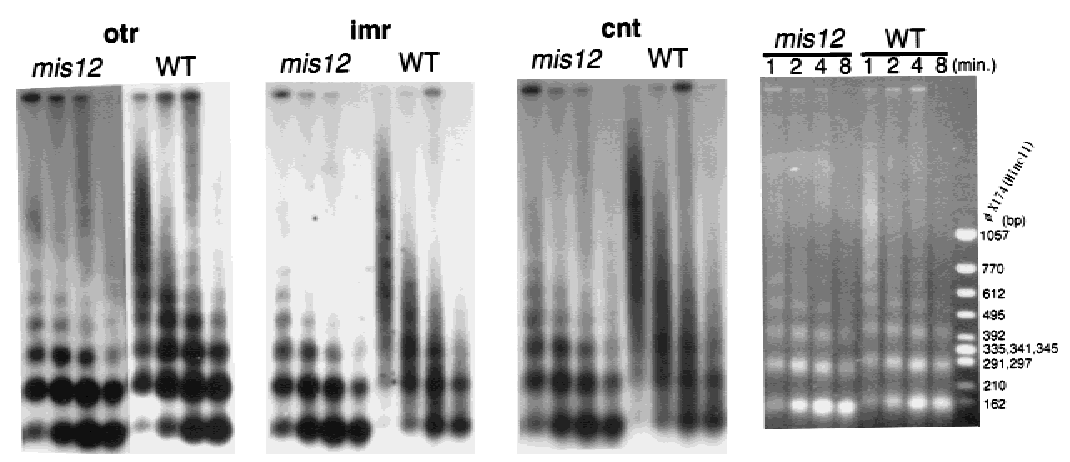

ing Mis12-HA (lanes 8,11) were constructed, and their formaldehyde-fixed extracts were immunoprecipitated by anti-HA antibody. Lanes 1-3 and 7-9 are the PCR products after immunoprecipitation; lanes 4-6 and 10-12 are the PCR products from the whole extracts. Wild-type-expressing Mis6-HA (lanes 1,4), Mis12-HA (lanes 7,10), and the wild-type 972 without the HA tag (lanes 3,6,9,12) were used as control. Mis6-HA could bind to the inner centromere regions (cnt1 and imrl) in mis12 at $36^{\circ} \mathrm{C}$, and vice versa. $(D)$ Nuclear chromatin was prepared from wild-type and the mis 12 mutant cultured at $36^{\circ} \mathrm{C}$ for $8 \mathrm{hr}$, and digested with micrococcal nuclease for $1,2,4$, and $8 \mathrm{~min}$, followed by agarose gel electrophoresis and Southern hybridization with the three DNA probes, otr1, imr1, and cnt1 (Saitoh et al. 1997). The ethidium-bromide staining patterns are shown at right with the size markers. The smeared nucleosome pattern in the inner centromere was abolished in mis12 mutant.

after the second division (4-8 hr) contained missegregation (unequal-sized nuclei). Coincident with the second mitosis, cell viability decreased. The cell number increase ceased after $8 \mathrm{hr}$. At $26^{\circ} \mathrm{C}$, however, mis 12 mutant cells showed normal chromosome segregation (data not shown).

Next, mis12-537 cells were arrested at $G_{1}$ by nitrogen starvation, and then released to the complete medium at $36^{\circ} \mathrm{C}$. Cell cycle progression was monitored by measuring DNA contents (Fig. 7C, left), missegregation frequency, and cell viability (right). The $\mathrm{S}$ phase occurred 3 $\mathrm{hr}$ after the shift to the complete medium at $36^{\circ} \mathrm{C}$, and the first and second mitosis, respectively, took place at 5-6 and 8-9 hr. In contrast to the case of mis6 mutant (Saitoh et al. 1997), the first mitosis was completely normal without the loss of cell viability. Missegregation was seen in the second round of mitosis (2nd M), consistent with a sharp decrease of cell viability only after the second mitosis. The cell number increase ceased after $10 \mathrm{hr}$.

One possibility is that Mis 12 is temperature sensitive for folding but not for function. To examine this possibility, we performed the following experiment: mis12-
537 cells were nitrogen starved to arrest in $\mathrm{G}_{1}$ at $26^{\circ} \mathrm{C}$, then cultured at $36^{\circ} \mathrm{C}$ under the same $\mathrm{G}_{1}$ condition for 4 $\mathrm{hr}$ and released to the rich YPD medium at $36^{\circ} \mathrm{C}$ (Fig. 7D). The first mitosis took place 9-10 hr after cells were exposed to $36^{\circ} \mathrm{C}$, but abnormal chromosome segregation was negligible $(\leq 4 \%)$. Only in the second mitosis (12 hr), was missegregation observed. Control $\mathrm{G}_{1}$-arrested culture was directly released to YPD at $36^{\circ} \mathrm{C}$, and $\sim 60 \%$ of the cells produced aberrant missegregation in the second mitosis that took place $9-10 \mathrm{hr}$ after the shift to $36^{\circ} \mathrm{C}$. This experimental result clearly showed that the delayed phenotype is not due to the rate of protein inactivation, and passing the first mitosis at $36^{\circ} \mathrm{C}$ is crucial to produce the phenotype. Mutant Mis12 protein was thus not temperature sensitive for folding but for function. Taken together, missegregation in mis12 occurred only after cells had passed through the previous mitosis to the subsequent mitosis at $36^{\circ} \mathrm{C}$ without proper Mis 12 function.

The cut 4 mis12 double-mutant strain carrying the integrated Mis6-GFP was constructed to examine whether sister centromeres could be prematurely separated in metaphase (cut4 is defective in polyubiquitination of mitotic cyclin and Cut2; Yamashita et al. 1996). The double 


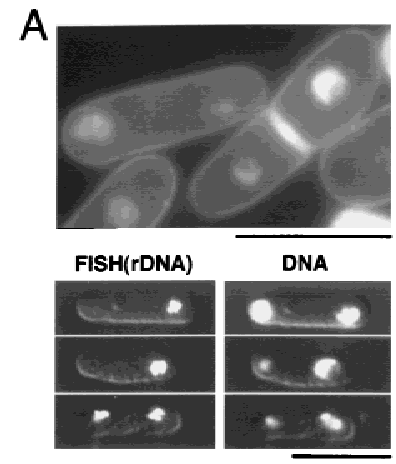

B
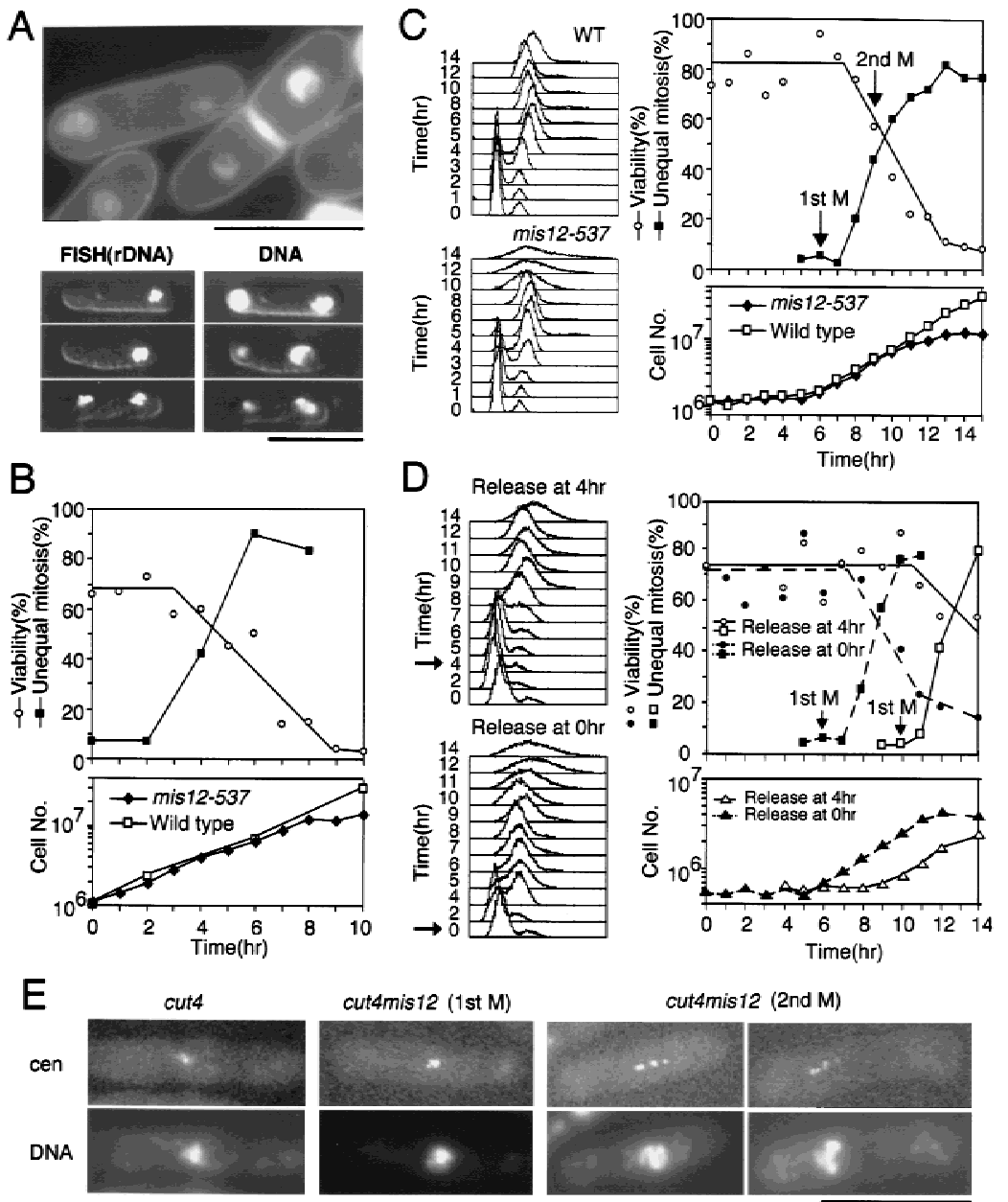

cut4mis12 (1st M)
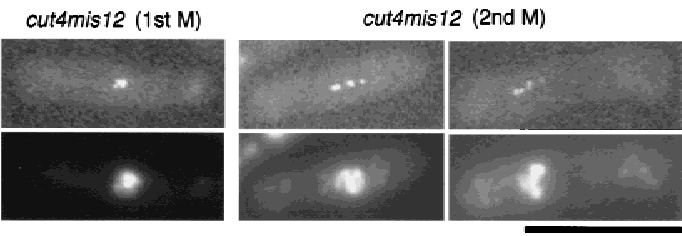

Figure 7. Missegregation occurs in mis12-537 after cells traverse the previous mitosis at $36^{\circ} \mathrm{C}$. $(A$, top) mis12-537 cells stained by DAPI after $8 \mathrm{hr}$ at $36^{\circ} \mathrm{C}$. Bar, $10 \mu \mathrm{m}$. (Bottom) FISH was applied with the probe of the rDNA repeats in chromosome III. The FISH signal was not separated in the top and middle cells, but was separated in the bottom. $(B)$ Asynchronously growing mis12 mutant cells (in the rich culture medium) were shifted to $36^{\circ} \mathrm{C}$ $\left(\right.$ most cells in $\left.\mathrm{G}_{2}\right)$. Frequencies of mutant cells displaying unequal nuclear division reached $80 \%$ after $6 \mathrm{hr}$ at $36^{\circ} \mathrm{C}$. Cell viability decreased after $4 \mathrm{hr}$, whereas cell number ceased to increase after $8 \mathrm{hr}$. (C) Wild type and mis12-537 were arrested at $\mathrm{G}_{1}$ by nitrogen starvation at $26^{\circ} \mathrm{C}$ in the synthetic medium and then released to the complete YPD medium at $36^{\circ} \mathrm{C}(0 \mathrm{hr})$. DNA contents determined by the FACScan are shown (left). The $S$ phase, the first and the second mitoses occurred at 3, 5-6, and 8-9 hr after the release, respectively, in mutant cells. The heterogeneous DNA contents appeared after the second cell division (right). Cell viability score decreased after $8 \mathrm{hr}$, whereas the frequency of missegregation was very low in the first mitosis but high in the second mitosis. The cell number increase in the mutant culture ceased after $10 \mathrm{hr}$. (D) mis12-537 was arrested at $\mathrm{G}_{1}$ by nitrogen starvation at $26^{\circ} \mathrm{C}$ in the synthetic medium, and shifted to $36^{\circ} \mathrm{C}$ in the same culture for $4 \mathrm{hr}$ : Cells did not grow under the starved condition. Cells were then released to the complete YPD medium at $36^{\circ} \mathrm{C}$ (release at $4 \mathrm{hr}$ ). In the control culture (release at $0 \mathrm{hr}$ ), cells were shifted to the complete YPD at $36^{\circ} \mathrm{C}$ without $4-\mathrm{hr}$ preincubation at $36^{\circ} \mathrm{C}$. DNA contents determined by the FACScan are shown (left). The $\mathrm{S}$ phase and the first $\mathrm{M}$ phase occurred after 7 and 9-10 hr in the culture released at $4 \mathrm{hr}$, respectively, whereas cell viability decreased after $12 \mathrm{hr}$ (in the second $\mathrm{M}$ phase). Chromosome missegregation (unequal mitosis percent) occurred in the second mitosis. All this occurred $4 \mathrm{hr}$ earlier in the control culture released at $0 \mathrm{hr}$. (E) The cut4 mis12 double mutant was grown as described in text. In the first metaphase, the signals of Mis6-GFP were clustered in the middle as the control single cut4, whereas they were split into four or five in the second metaphase at $36^{\circ} \mathrm{C}$. Bar, $10 \mu \mathrm{m}$.

mutant was first cultured in the synthetic EMM2 at $36^{\circ} \mathrm{C}$ for $3.5 \mathrm{hr}$ and then at $36^{\circ} \mathrm{C}$ in the complete YPD for $3 \mathrm{hr}$. The signal of Mis6-GFP was then observed in methanol-fixed cells. Under this culture condition, the second mitosis could take place as cut4 was able to go through mitosis in the synthetic EMM2 at $36^{\circ} \mathrm{C}$ (Yamashita et al. 1996). The Mis6-GFP signals were frequently resolved in four to six dots in the second mitosis of cut4 mis12 (Fig. 7E, right), suggesting that sister centromeres were separated in the metaphase-arrested cells. However, less than three signals were observed in mitotically arrested single cut4 mutant cells (left). The Mis6-GFP signal in the first mitosis of cut4 mis12 (middle) was similar to that of single cut4.

mis12 suppresses dis1, whereas cold-sensitive mutations leading to normal spindle length suppress mis12

To identify gene products that might interact with Mis12, we made a number of crosses between mis12-537 and known mitotic mutations. We found that mis12-537 (but not mis6) could suppress the cold-sensitive phenotype of dis1 mutation (Fig. 8A). Dis1 plays a role in linking the kinetochore to the mitotic SPBs (Nabeshima et al. 1998). In the dis1 mutant, the prophase spindle continued to elongate without sister chromatid separation. Suppression did not work in the opposite direction, however: The temperature-sensitive phenotype of mis 12 was not suppressed by the dis 1 null. Instead, at $33^{\circ} \mathrm{C}$, the double-mutant mis12 dis1 null was synthetically lethal. These results suggested that Mis12 is functionally related to Dis1.

We screened for mutations that could suppress the temperature-sensitive phenotype of mis12-537 and isolated 500 spontaneous revertants that produced colonies at $36^{\circ} \mathrm{C}$. Twenty four of them were cold sensitive; they were unable to form colonies at $22^{\circ} \mathrm{C}$. Although genetic analyses of the mutants have not been completed, all of these mutants curiously display deviation from the rod shape. Identification of the genes responsible for the cold-sensitive mutations is under investigation. Two 
Goshima et al.

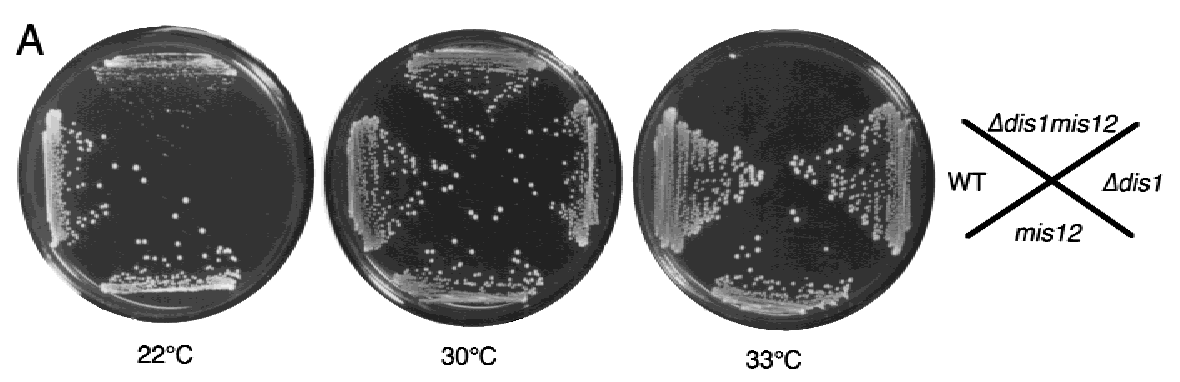

Figure 8. Interaction of mis12 and coldsensitive mutations. (A) The double mutant between temperature-sensitive mis12 and cold-sensitive dis1 null produced small colonies at $22^{\circ} \mathrm{C}$, whereas it failed to produce colonies at $33^{\circ} \mathrm{C}$. (B) Two cold-sensitive suppressors (strains 163 and 165 ) isolated were able to grow at $36^{\circ} \mathrm{C}$. They were stained by anti-Sad1 antibodies and the pole-to-pole distance in mitotic cells was measured. The number of cells are indicated as the frequency. The open and solid arrowheads indicated the sizes of wild-type and mis12 spindle at metaphase.
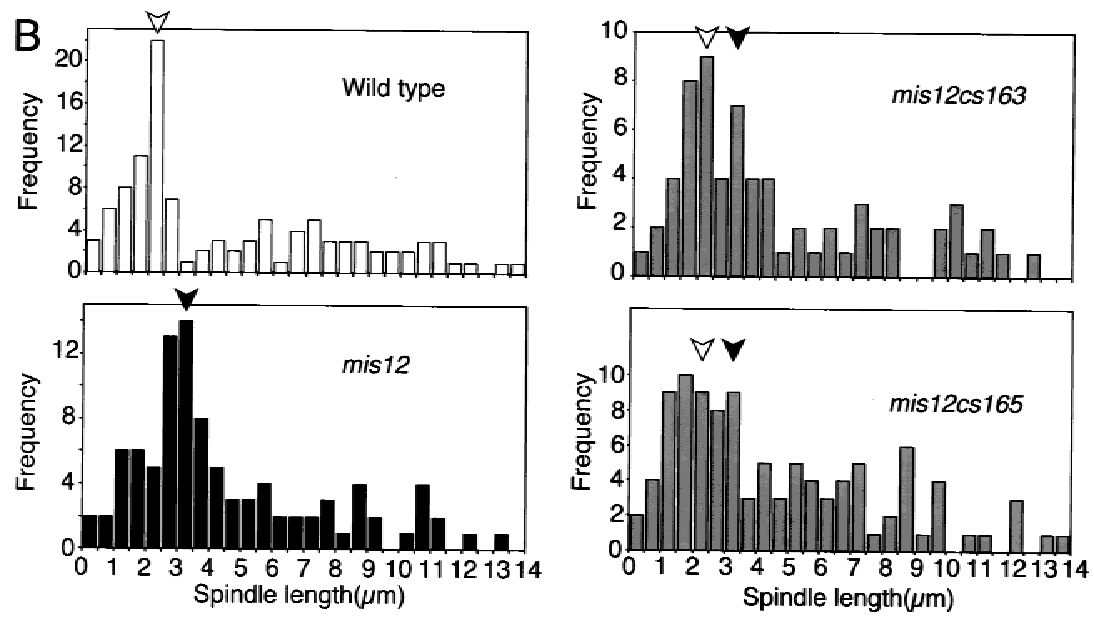

strains, 163 and 165, were examined to learn whether suppression of the temperature-sensitive phenotype of mis12 led to the decrease in spindle length. Mutant cells were stained by anti-sad 1 antibodies, and their pole-topole distance in mitotic cells was measured at $36^{\circ} \mathrm{C}$ (Fig. $8 \mathrm{~B})$. For both strains, the spindle length in a large fractions of cells was identical to that of the wild type (open arrowheads), showing that the mis12 phenotype of long metaphase spindle was greatly diminished when suppressor mutations were combined. These results are consistent with the hypothesis that metaphase spindle expansion and drastic missegregation in mis12 are closely related.

\section{Discussion}

This paper reports a novel centromere protein, Mis12, in fission yeast. It is essential for viability, and its loss leads to a dramatic missegregation of chromosomes. It is not required for sister chromatid separation, but is absolutely required for correct segregation of chromosomes. Budding yeast Mtwlp shares similarity with Mis12 in the amino-terminal sequence and the central putative coiled-coil motif. Gene disruption indicates that MTW1 is essential for viability with the cell cycle arrest phenotype showing a large bud with the nucleus often located in the neck between two daughter cells (G. Goshima and M. Yanagida, unpubl.). Mtwlp is not included in the known centromere-interacting proteins. Intracellular localization of Mtwlp remains to be determined.

Certain properties of Mis12 are similar to Mis6 (Saitoh et al. 1997). Both colocalize at the centromeres, and coprecipitate with the inner centromere DNAs rich in A or $\mathrm{T}$ clusters. The inner centromere-specific chromatin structure is abolished in mis12 as in mis6 cells. Therefore, Mis12 and Mis6 proteins are essential for creating the architecture of the inner centromere. Moreover, both Mis6 and Mis12 were discovered to affect spindle length during the metaphase-anaphase transition period. We assume that this property is important for faithful chromosome segregation (see below). A budding yeast kinetochore protein Ctf19p, which provides a link between the mitotic spindle and the kinetochore (Hyland et al. 1999), might have similar function. Mis6 and Mis12 differ considerably in other aspects. They neither cosediment nor are coimmunoprecipitated, indicating that they do not function together in the same complex. Mis12 (but not Mis6) interacts with Dis1 (Nabeshima et al. 1995; Nakaseko et al. 1996), possible mediator between kinetochores and the SPBs. Bipolar spindle assembly in budding yeast is achieved by motors that antagonize each other by exerting forces in opposite directions (Hoyt et al. 1997). Considering the continuous elongation of the prophase spindle in dis1 because of the lack of pulling force (Nabeshima et al. 1998) and abnormal metaphase spindle length in mis12 perhaps due to the loss of sister-centromere cohesion, their double-mutant phenotype might be obtained by the change in the force balance in the spindle.

Mis12 seems to function in the previous $M$ phase for proper chromosome segregation. This surprising conclusion is reached on the basis of several results. If Mis12 is 
inactive from $G_{1}$ (or from $G_{2}$ ), the immediate mitosis is completely normal, but in the second round of mitosis, viability sharply decreases with extensive chromosome missegregation. Preheating in $\mathrm{G}_{1}$ for $4 \mathrm{hr}$ at $36^{\circ} \mathrm{C}$ confirmed that Mis12 had to be inactive in the first mitosis for producing missegregation in the second mitosis. Sister centromeres were prematurely separated at metaphase in the second mitosis. An interpretation of these results is that sister centromeres are connected by the action of functional Mis12. A simple model is that Mis12 may establish a centromere structure during the first mitosis that can be built on to ensure correct segregation in the second mitosis. Mis6 association with centromeres is not dependent on Mis12, thus, at least two independent functions must exist. One implication is that drastic missegregation occurs only when the mutant Mis12 protein is inactivated from the first $M$ through to the second $M$ phase. This would be a highly effective way to maintain segregation fidelity of chromosomes, as the centromere defect due to mis12 mutation could be repaired over a broad time span even in late $G_{2}$ if active Mis12 were supplied. Missegregation occurs in the mis6 mutant if Mis6 is continuously inactive from $G_{1}$ to $M$ (Saitoh et al. 1997). The defect could be fixed if active Mis6 were supplied anytime from $G_{1} / S$ to $M$. These late remedy systems explain a part of the high fidelity in chromosome segregation. We found recently that a class of centromere chromatin protein was localized at the centromere in a Mis6 (but not Mis12)-dependent manner, supporting the theory that Mis6 and Mis 12 are functionally distinct (K. Takahashi and M. Yanagida, in prep.).

Two other conclusions emerging from the present study may have some general implications. One is that centromere-connecting proteins actively participate in correct morphogenesis of the mitotic spindle. Mutations in the centromere proteins affect overall spindle size. Kinetochores, however, are apparently not required for spindle formation per se. Heald et al. $(1996,1997)$ demonstrated using frog extracts that microtubules and DNA beads self-assemble into the bipolar spindle structure in the absence of centrosomes and kinetochores. Functional kinetochores were not required for the assembly of a bipolar spindle in budding yeast (Sorger et al. 1995). The present study showed that the kinetochore proteins are a major determinant for correct metaphase spindle length in fission yeast. Expansion of the metaphase spindle is not due to extension of the centromere DNAs; neither cen1-GFP (this study) nor GFP-Mis6 (data not shown) revealed any stretching of the centromere signals in mutant cells.

The expanded metaphase spindle might be explained by defects in the steps leading to correct spindle morphogenesis. Alternatively, it might be explained by the unbalanced force in the spindle. The metaphase spindle length can be assumed to be set by the point at which the force that the linked sister kinetochores exert to pull the poles toward each other is balanced by other, kinetochore-independent forces that tend to push the poles apart from each other. In mis12 and mis6 mutants, de- fects in kinetochore function and sister kinetochore linkage diminish the force that pulls the poles toward each other, resulting in the force balance causing the longer metaphase spindle. The metaphase spindle length became normal and the frequency of missegregation was greatly reduced at $36^{\circ} \mathrm{C}$ when cold-sensitive suppressor mutations were combined with mis12-537. In these suppressor mutants, the kinetochore function might be strengthened, inducing the stronger pulling force of the poles, which in turn reduces the length of the metaphase spindle. We recently found that the metaphase spindle in one cold-sensitive mutant is shorter than normal at the permissive temperature (G. Goshima et al., unpubl.). We consider that both models, defective in the force balance or the spindle-size control, are equally possible in causing chromosome missegregation. These two models, however, are not necessarily mutually exclusive, because the longer the spindle is, the more difficult it will be for a kinetochore that is close to one pole to be captured by microtubules that emanate from the opposite pole. The expanded metaphase spindle thus may have a crucial relation to the missegregation phenotype.

The other conclusion is that all three phases of spindle dynamics exist in mis6 and mis12, although the metaphase spindle is exceedingly long. The decrease in the fidelity of sister-chromatid separation is not due to the loss of the spindle pulling force, as the unequal-sized daughter nuclei were fully separated. Full extension of the spindle in mis6 and mis12 suggests that defects in these mutants do not activate spindle checkpoint. Mis6 and Mis12 may be involved in recruiting the checkpoint components onto the spindle, so that the spindle made in mis6 and mis12 mutants is deficient in spindle checkpoint. This possibility can be tested, but other explanations also are possible.

How, then, are sister chromatids missegregated in mis6 and mis12 mutants in spite of the presence of apparently normal spindle extension? We have no firm answer to this important question, other than the longer metaphase spindle discussed above. One clue is that we have not observed lagging chromosomes in mis12 (or mis6) mutants. Lagging chromosomes located along the elongated anaphase spindle are found in many mutants (Ohkura et al. 1988; Ekwall et al. 1995). In mis6 and mis12, however, chromosomes are always brought to the poles. Behavior of the cen1-GFP signal visualized in mis12 is another clue to understanding missegregation. In $>50 \%$ of mis 12 cells, the cen 1 signals are rapidly separated toward the poles as in wild type, but in the remaining cell populations, the cen1-GFP signals behave abnormally. These results suggest that there is a high probability that the "entry gate" into sister centromere separation, rather than the force-generating machinery for this separation, is defective in mutant cells. Aberrant sister centromeres separate only after they move along on the elongating anaphase B spindle, remaining in one side of the cell. One of the sister kinetochores may not function properly, or the link between one kinetochore and one pole may be broken immediately before anaphase. Biorientation of the sister chromatids in the 
spindle may be impaired as hypothesized previously (Saitoh et al. 1997), so that one sister kinetochore frequently becomes defective in interacting with the kinetochore microtubules. Alternatively, biorientation is established, but the link between the kinetochore and the pole is fragile because of the elongated metaphase spindle, so that the trigger of anaphase spindle movement may break one of the two pole-to-kinetochore connections. In another case, microtubules from the same direction might capture the sister centromeres of one chromosome that have lost biorientation so that the sister chromatids would be brought to the same pole, whereas other chromosomes are correctly separated by spindle extension. These cases are thought to be possible causes for aneuploidy. Molecular understanding of the centromere defects would be crucial for solving the highfidelity segregation mechanism supported by Mis6 and Mis12.

\section{Materials and methods}

Strains, media, and culture media

The complete YPD ( $1 \%$ yeast extract, $2 \%$ polypeptone, $2 \%$ glucose) and the minimal EMM2 medium (Mitchison 1970) were used for the culture of $S$. pombe. EMM2-N was used for nitrogen starvation. LB medium $(0.5 \%$ yeast extract, $1 \%$ polypeptone, $1 \% \mathrm{NaCl}$ at $\mathrm{pH} 7.5)$ was used to grow Escherichia coli MM294. S. pombe mutant strains mis12-537, mis6-302, mis4-242, cut9665, and nda3-KM311 were described previously (Hiraoka et al. 1984; Takahashi et al. 1994; Saitoh et al. 1997; Yamada et al. 1997; Furuya et al. 1998). S. pombe strain used for visualization of cen1-GFP was described previously (Nabeshima et al. 1998). The strain MKY7B-8 containing plasmid with GFP-LacI-NLS under the nmt1 promoter was a modification of the MKY7A-4 strain described. This strain was grown in the presence of $2 \mu \mathrm{M}$ thiamine.

\section{Isolation of the mis $12^{+}$gene}

The mis $12^{+}$gene was isolated by chromosome mapping and cosmid walking. By extensive crossing, mis12-537 was mapped near cut3 $(10 \mathrm{~cm})$ and $s d s 23(21 \mathrm{~cm})$ in chromosome II. Cosmids in this region (146, 337, 1734, 1709, 409; Mizukami et al. 1993) were introduced into mis12-537 by transformation with a helper plasmid pYC11 (Chikashige et al. 1989). Cosmid c409 could suppress the temperature-sensitive phenotype of mis12537, and subsequent subcloning yielded a minimal functional fragment that was integrated onto the chromosome by homologous recombination; this was confirmed to contain the mis $12^{+}$ gene as the integrated fragment with the marker gene tightly linked to the mis12-537 locus (PD:NPD:TT=32:0:0). The mis $12^{+}$gene thus isolated was adjacent to a gene highly similar to Skp1 (Zhang et al. 1995; Connelly and Hieter 1996) that did not rescue the temperature-sensitive phenotype of mis12-537.

\section{Gene disruption}

One-step gene replacement (Rothstein 1983) was used. Plasmid pGG704 contained the insert for the full-length mis12 ${ }^{+}$gene. EcoRI-AatII fragment $(0.7 \mathrm{~kb})$ in the coding region was replaced with the $S$. pombe ura4 $4^{+}$gene, and the Eco47III-BamHI fragment containing the disrupted mis12 gene was used for transformation of a diploid 5A/1D $\left(\mathrm{h}^{-} / \mathrm{h}^{+}\right.$leu1/leu1 ura4/ura4 his2/+ ade6-M210/ade6-M216) . Ura ${ }^{+}$heterozygous transformant cells thus obtained were dissected by tetrad analysis. Gene disruption was verified by Southern blotting of the genomic DNA of the diploid (data not shown). Only two spores were viable, and those spores were $\mathrm{Ura}^{-}$, indicating that Mis 12 was absolutely essential for cell viability. The phenotype of genedisrupted cells was obtained by germinating the spores made from heterozygous diploid cells in the EMM2 (supplemented by Leu, His, and Ade) at $33^{\circ} \mathrm{C}$. Cells were observed after $10-19 \mathrm{hr}$ by DAPI stain.

\section{Plasmids}

pTN501, a derivative of pSD8 (Nabeshima et al. 1998), was used for observation of Sad1, a SPB protein. This plasmid contains EGFP (Clontech) instead of the wild-type GFP and produces more intense Sad1-GFP signal. Multicopy plasmid pMC12-GFP and pMC12-HA was constructed by tagging the GFP (S65T) or 3XHA at the carboxyl terminus of the mis $12^{+}$gene; a 700-bp long $5^{\prime}$-upstream sequence was included. The $8 \times$ Myc tag was added to the carboxyl terminus of the mis $6^{+}$gene by PCR amplification of the Myc epitope. Mis12-GFP, Mis12-HA, and Mis6-Myc were integrated onto the genome by an integration vector pYC11 as described (Nabeshima et al. 1997).

\section{Microscopy}

DAPI staining was done as described (Adachi et al. 1989). The procedures for immunofluorescence microscopy were described by Hagan and Hyams (1988). Cells were fixed by methanol or formaldehyde, and stained by TAT1 antibody (Woods et al. 1989). Hoechst 33342 was used for the DNA stain in living cells (Chikashige et al. 1994). The FISH method was performed as described (Funabiki et al. 1993) with the probe of rDNA YIp10.4 and the centromere repeat probe pRS140. A confocal microscope MRC-1024 (Bio-Rad) was used to observe living cells. Images were taken at $30-\mathrm{sec}$ intervals. The culture of $S$. pombe for microscopy was followed as described in Nabeshima et al. (1997), although concanavalin A was not used.

\section{Isolation of cold-sensitive suppressors}

Haploid $h^{-}$leu1 mis12-537 cells grown at $26^{\circ} \mathrm{C}$ were plated on YPD at $36^{\circ} \mathrm{C}$ for 4 days. Five hundred $\mathrm{Ts}^{+}$revertants were obtained from $5 \times 10^{9}$ cells, of which 24 strains did not produce colonies at $22^{\circ} \mathrm{C}$. These $\mathrm{Ts}^{+} \mathrm{Cs}^{-}$strains were cultured at $36^{\circ} \mathrm{C}$ and stained by anti-Sad1 antibodies.

\section{Nitrogen starvation}

The procedures for nitrogen source starvation experiments with cut9 mis6 and cut9 mis 4 were described previously (Saitoh et al. 1997; Furuya et al. 1998). Single mis12 mutant cells $\left(5 \times 10^{6} / \mathrm{ml}\right.$ grown in EMM2 at $26^{\circ} \mathrm{C}$ ) were washed in EMM2-N and the concentrated cell suspension $\left(2 \times 10^{7} / \mathrm{ml}\right)$ was cultured at $26^{\circ} \mathrm{C}$ for $22 \mathrm{hr}$. Cells were then released into the rich YPD medium and cultured at $36^{\circ} \mathrm{C}$. The procedures of FACScan analysis were described previously (Costello et al. 1986).

\section{Chromatin immunoprecipitation, micrococcal nuclease digestion, and immunological methods}

The Chip method adapted to $S$. pombe was described in Saitoh et al. (1997). For mis6 and mis12 mutant strains, cells cultured at $36^{\circ} \mathrm{C}$ for $6 \mathrm{hr}$ were used for formaldehyde fixation. The procedures for micrococcal nuclease digestion were described by 
Takahashi et al (1992) with a modification. Cells were cultured at $36^{\circ} \mathrm{C}$ for $8 \mathrm{hr}$, and treated with micrococcal nuclease $(250$ $\mathrm{U} / \mathrm{ml}$, Worthington Biochem). Plasmids pKT110, pKT108, and pYC148 were used as hybridization probes. For immunoblotting and precipitation, cell extracts were prepared with the HB buffer (Moreno et al. 1989). Immunoprecipitation was done by antiHA antibody (12CA5, BAbCO) conjugated with protein A-Sepharose. Anti-Myc antibody 9E10 (Calbiochem) was used.

\section{Acknowledgments}

The present study was supported by CREST of Japan Science and Technology Corporation, and a grant from the Human Frontier Science Project Organization. S.S. acknowledges the Japan Society for Promotion of Science, which awarded him a predoctoral research fellowship.

The publication costs of this article were defrayed in part by payment of page charges. This article must therefore be hereby marked 'advertisement' in accordance with 18 USC section 1734 solely to indicate this fact.

\section{Note added in proof}

The nucleotide sequence data reported in this paper will appear in DDBJ, EMBL, and GenBank nucleotide sequence databases under the following accession numbers: AB027472 for the $S$. pombe mis $12^{+}$gene and the p19SKP1-like gene; AB027473 for the $S$. cerevisiae MTW1 gene.

\section{References}

Adachi, Y. and M. Yanagida. 1989. Higher order chromosome structure is affected by cold-sensitive mutations in a Schizosaccharomyces pombe gene $\mathrm{crm} 1^{+}$which encodes a $115-\mathrm{kD}$ protein preferentially localized in the nucleus and its periphery. J. Cell. Biol. 108: 1195-1207.

Chen, R.H., J.C. Waters, E.D. Salmon, and A.W. Murray. 1996. Association of spindle assembly checkpoint component XMAD2 with unattached kinetochores. Science 274: 242 246.

Chikashige, Y., N. Kinoshita, Y. Nakaseko, T. Matsumoto, S. Murakami, O. Niwa, and M. Yanagida. 1989. Composite motifs and repeat symmetry in S. pombe centromeres: Direct analysis by integration of NotI restriction sites. Cell 57: 739751.

Chikashige, Y., D.Q. Ding, H. Funabiki, T. Haraguchi, S. Mashiko, M. Yanagida, and Y. Hiraoka. 1994. Telomere-led premeiotic chromosome movement in fission yeast. Science 264: 270-273.

Ciosk, R., W. Zachariae, C. Michaelis, A. Shevchenko, M. Mann, and K. Nasmyth. 1998. An ESP1/PDS1 complex regulates loss of sister chromatid cohesion at the metaphase to anaphase transition in yeast. Cell 93: 1067-1076.

Clarke, L. 1998. Centromeres: Proteins, protein complexes, and repeated domains at centromeres of simple eukaryotes. Curr. Opin. Genet. Dev. 8: 212-218.

Cohen-Fix, O., J.M. Peters, M.W. Kirschner, and D. Koshland. 1996. Anaphase initiation in Saccharomyces cerevisiae is controlled by the APC-dependent degradation of the anaphase inhibitor Pds1p. Genes \& Dev. 10: 3081-3093.

Connelly, C. and P. Hieter. 1996. Budding yeast SKP1 encodes an evolutionarily conserved kinetochore protein required for cell cycle progression. Cell 86: 275-285.
Costello, G., L. Rodger, and D. Beach. 1986. Fission yeast enters the stationary phase G0 state from either mitotic G1 or G2. Curr. Genet. 11: 119-125.

Csink, A.K. and S. Henikoff. 1998. Something from nothing: The evolution and utility of satellite repeats. Trends Genet. 14: 200-204.

Ekwall, K., J.P. Javerzat, A. Lorentz, H. Schmidt, G. Cranston, and R. Allshire. 1995. The chromodomain protein Swi6: A key component at fission yeast centromeres. Science 269: 1429-1431.

Ekwall, K., T. Olsson, B.M. Turner, G. Cranston, and R.C. Allshire. 1997. Transient inhibition of histone deacetylation alters the structural and functional imprint at fission yeast centromeres. Cell 91: 1021-1032.

Espelin, C.W., K.B. Kaplan, and P.K. Sorger. 1997. Probing the architecture of a simple kinetochore using DNA-protein crosslinking. J. Cell. Biol. 139: 1383-1396.

Funabiki, H., I. Hagan, S. Uzawa, and M. Yanagida. 1993. Cell cycle-dependent specific positioning and clustering of centromeres and telomeres in fission yeast. J. Cell. Biol. 121: 961-976.

Funabiki, H., K. Kumada, and M. Yanagida. 1996a. Fission yeast Cut 1 and Cut 2 are essential for sister chromatid separation, concentrate along the metaphase spindle and form large complexes. EMBO J. 15: 6617-6628.

Funabiki, H., H. Yamano, K. Kumada, K. Nagao, T. Hunt, and M. Yanagida. 1996b. Cut2 proteolysis required for sisterchromatid separation in fission yeast. Nature 381: 438-441.

Funabiki, H., H. Yamano, K. Nagao, H. Tanaka, H. Yasuda, T. Hunt, and M. Yanagida. 1997. Fission yeast Cut2 required for anaphase has two destruction boxes. EMBO J. 16:59775987.

Furuya, K., K. Takahashi, and M. Yanagida. 1998. Faithful anaphase is ensured by Mis4, a sister chromatid cohesion molecule required in $S$ phase and not destroyed in $G_{1}$ phase. Genes \& Dev. 12: 3408-3418.

Gordon, C., G. McGurk, P. Dillon, C. Rosen, and N.D. Hastie. 1993. Defective mitosis due to a mutation in the gene for a fission yeast 26 S protease subunit. Nature 366: 355-357.

Guacci, V., D. Koshland, and A. Strunnikov. 1997. A direct link between sister chromatid cohesion and chromosome condensation revealed through the analysis of MCD1 in S. cerevisiae. Cell 91: 47-57.

Hagan, I. and M. Yanagida. 1995. The product of the spindle formation gene $\operatorname{sad1}^{+}$associates with the fission yeast spindle pole body and is essential for viability. J. Cell. Biol. 129: 1033-1047.

Hagan, I.M. and J.S. Hyams. 1988. The use of cell division cycle mutants to investigate the control of microtubule distribution in the fission yeast Schizosaccharomyces pombe. J. Cell. Sci. 89: 343-357.

Heald, R., R. Tournebize, T. Blank, R. Sandaltzopoulos, P. Becker, A. Hyman, and E. Karsenti. 1996. Self-organization of microtubules into bipolar spindles around artificial chromosomes in Xenopus egg extracts. Nature 382: 420-425.

Heald, R., R. Tournebize, A. Habermann, E. Karsenti, and A. Hyman. 1997. Spindle assembly in Xenopus egg extracts: Respective roles of centrosomes and microtubule self-organization. J. Cell. Biol. 138: 615-628.

Hirano, T., Y. Hiraoka, and M. Yanagida. 1988. A temperaturesensitive mutation of the Schizosaccharomyces pombe gene $n u c 2^{+}$that encodes a nuclear scaffold-like protein blocks spindle elongation in mitotic anaphase. J. Cell. Biol. 106: 1171-1183.

Hiraoka, Y., T. Toda, and M. Yanagida. 1984. The NDA3 gene of fission yeast encodes beta-tubulin: A cold-sensitive nda3 
mutation reversibly blocks spindle formation and chromosome movement in mitosis. Cell 39: 349-358.

Hoyt, M.A., A.A. Hyman, and M. Bahler. 1997. Motor proteins of the eukaryotic cytoskeleton. Proc. Natl. Acad. Sci. 94: $12747-12748$.

Hyland, K.M., J. Kingsbury, D. Koshland, and P. Hieter. 1999. Ctf19p: A novel kinetochore protein in Saccharomyces cerevisiae and a potential link between the kinetochore and mitotic spindle. J. Cell. Biol. 145: 15-28.

Ikeno, M., B. Grimes, T. Okazaki, M. Nakano, K. Saitoh, H. Hoshino, N.I. McGill, H. Cooke, and H. Masumoto. 1998. Construction of YAC-based mammalian artificial chromosomes. Nat. Biotechnol. 16: 431-439.

Karpen, G.H. and R.C. Allshire. 1997. The case for epigenetic effects on centromere identity and function. Trends Genet. 13: 489-496.

Kim, S.H., D.P. Lin, S. Matsumoto, A. Kitazono, and T. Matsumoto. 1998. Fission yeast Slp1: An effector of the Mad2dependent spindle checkpoint. Science 279: 1045-1047.

King, R.W., J.M. Peters, S. Tugendreich, M. Rolfe, P. Hieter, and M.W. Kirschner. 1995. A 20S complex containing CDC27 and CDC16 catalyzes the mitosis-specific conjugation of ubiquitin to cyclin B. Cell 81: 279-288.

Kumada, K., T. Nakamura, K. Nagao, H. Funabiki, T. Nakagawa, and M. Yanagida. 1998. Cut1 is loaded onto the spindle by binding to Cut 2 and promotes anaphase spindle movement upon Cut2 proteolysis. Curr. Biol. 8: 633-641.

Losada, A., M. Hirano, and T. Hirano. 1998. Identification of Xenopus SMC protein complexes required for sister chromatid cohesion. Genes \& Dev. 12: 1986-1997.

Meluh, P.B., P. Yang, L. Glowczewski, D. Koshland, and M.M. Smith. 1998. Cse4p is a component of the core centromere of Saccharomyces cerevisiae. Cell 94: 607-613.

Michaelis, C., R. Ciosk, and K. Nasmyth. 1997. Cohesins: Chromosomal proteins that prevent premature separation of sister chromatids. Cell 91: 35-45.

Mitchison, J.M. 1970. Physiological and cytological methods for Schizosaccharomyces pombe. Methods Cell Physiol. 4: 131-165.

Miyazaki, W.Y. and T.L. Orr-Weaver. 1994. Sister-chromatid cohesion in mitosis and meiosis. Annu. Rev. Genet. 28: 167187.

Mizukami, T., W.I. Chang, I. Garkavtsev, N. Kaplan, D. Lombardi, T. Matsumoto, O. Niwa, A. Kounosu, M. Yanagida, T.G. Marr, and D. Beach. 1993. A $13 \mathrm{~kb}$ resolution cosmid map of the $14 \mathrm{Mb}$ fission yeast genome by nonrandom sequence-tagged site mapping. Cell 73: 121-132.

Moore, D.P., A.W. Page, T.T. Tang, A.W. Kerrebrock, and T.L. Orr-Weaver. 1998. The cohesion protein MEI-S332 localizes to condensed meiotic and mitotic centromeres until sister chromatids separate. J. Cell. Biol. 140: 1003-1012.

Moreno, S., J. Hayles, and P. Nurse. 1989. Regulation of p34cdc2 protein kinase during mitosis. Cell 58: 361-372.

Nabeshima, K., H. Kurooka, M. Takeuchi, K. Kinoshita, Y. Nakaseko, and M. Yanagida. 1995. p93dis1, which is required for sister chromatid separation, is a novel microtubule and spindle pole body-associating protein phosphorylated at the Cdc2 target sites. Genes \& Dev. 9: 1572-1585.

Nabeshima, K., S. Saitoh, and M. Yanagida. 1997. Use of green fluorescent protein for intracellular protein localization in living fission yeast cells. Methods Enzymol. 283: 459-471.

Nabeshima, K., T. Nakagawa, A.F. Straight, A. Murray, Y. Chikashige, Y.M. Yamashita, Y. Hiraoka, and M. Yanagida. 1998. Dynamics of centromeres during metaphase-anaphase transition in fission yeast: Dis 1 is implicated in force balance in metaphase bipolar spindle. Mol. Biol. Cell 9: 32113225 .
Nakaseko, Y., K. Nabeshima, K. Kinoshita, and M. Yanagida. 1996. Dissection of fission yeast microtubule associating protein p93Dis1: Regions implicated in regulated localization and microtubule interaction. Genes Cells 1: 633-644.

Nasmyth, K. 1999. Separating sister chromatids. Trends Biochem. Sci. 24: 98-104.

Ohkura, H., Y. Adachi, N. Kinoshita, O. Niwa, T. Toda, and M. Yanagida. 1988. Cold-sensitive and caffeine-supersensitive mutants of the Schizosaccharomyces pombe dis genes implicated in sister chromatid separation during mitosis. EMBO J. 7: 1465-1473.

Polizzi, C. and L. Clarke. 1991. The chromatin structure of centromeres from fission yeast: Differentiation of the central core that correlates with function. J. Cell. Biol. 112: 191201.

Rieder, C.L. and E.D. Salmon. 1998. The vertebrate cell kinetochore and its roles during mitosis. Trends Cell. Biol. 8: 310318.

Rothstein, R.J. 1983. One-step gene disruption in yeast. Methods Enzymol. 101: 202-211.

Saitoh, S., K. Takahashi, and M. Yanagida. 1997. Mis6, a fission yeast inner centromere protein, acts during G1/S and forms specialized chromatin required for equal segregation. Cell 90: $131-143$

Skibbens, R.V., L.B. Corson, D. Koshland, and P. Hieter. 1999. Ctf7p is essential for sister chromatid cohesion and links mitotic chromosome structure to the DNA replication machinery. Genes \& Dev. 13: 307-319.

Sorger, P.K., K.F. Doheny, P. Hieter, K.M. Kopski, T.C. Huffaker, and A.A. Hyman. 1995. Two genes required for the binding of an essential Saccharomyces cerevisiae kinetochore complex to DNA. Proc. Nat1. Acad. Sci. 92: 1202612030.

Sudakin, V., D. Ganoth, A. Dahan, H. Heller, J. Hershko, F.C. Luca, J.V. Ruderman, and A. Hershko. 1995. The cyclosome, a large complex containing cyclin-selective ubiquitin ligase activity, targets cyclins for destruction at the end of mitosis. Mol. Biol. Cell 6: 185-197.

Sun, X., J. Wahlstrom, and G. Karpen. 1997. Molecular structure of a functional Drosophila centromere. Cell 91: 1007-1019.

Takahashi, K., S. Murakami, Y. Chikashige, H. Funabiki, O Niwa, and M. Yanagida. 1992. A low copy number central sequence with strict symmetry and unusual chromatin structure in fission yeast centromere. Mol. Biol. Cell 3: 819835.

Takahashi, K., H. Yamada, and M. Yanagida. 1994. Fission yeast minichromosome loss mutants mis cause lethal aneuploidy and replication abnormality. Mol. Biol. Cell 5: 1145-1158.

Toth, A., R. Ciosk, F. Uhlmann, M. Galova, A. Schleiffer, and K Nasmyth. 1999. Yeast cohesin complex requires a conserved protein, Ecolp (Ctf7), to establish cohesion between sister chromatids during DNA replication. Genes \& Dev. 13: 320333

Uhlmann, F. and K. Nasmyth. 1998. Cohesion between sister chromatids must be established during DNA replication. Curr. Biol. 8: 1095-1101.

Willard, H.F. 1998. Centromeres: The missing link in the development of human artificial chromosomes. Curr. Opin. Genet. Dev. 8: 219-225.

Williams, B.C., T.D. Murphy, M.L. Goldberg, and G.H. Karpen. 1998. Neocentromere activity of structurally acentric minichromosomes in Drosophila. Nat. Genet. 18: 30-37.

Woods, A., T. Sherwin, R. Sasse, T.H. MacRae, A.J. Baines, and K. Gull. 1989. Definition of individual components within the cytoskeleton of Trypanosoma brucei by a library of monoclonal antibodies. J. Cell. Sci. 93: 491-500. 
Yamada, H., K. Kumada, and M. Yanagida. 1997. Distinct subunit functions and cell cycle regulated phosphorylation of 20S APC/cyclosome required for anaphase in fission yeast. J. Cell. Sci. 110: 1793-1804.

Yamamoto, A., V. Guacci, and D. Koshland. 1996. Pds1p, an inhibitor of anaphase in budding yeast, plays a critical role in the APC and checkpoint pathway(s). J. Cell. Biol. 133: 99110.

Yamano, H., J. Gannon, and T. Hunt. 1996. The role of proteolysis in cell cycle progression in Schizosaccharomyces pombe. EMBO T. 15: 5268-5279.

Yamashita, Y.M., Y. Nakaseko, I. Samejima, K. Kumada, H. Yamada, D. Michaelson, and M. Yanagida. 1996. 20S cyclosome complex formation and proteolytic activity inhibited by the cAMP/PKA pathway. Nature 384: 276-279.

Yanagida, M. 1998. Fission yeast cut mutations revisited: Control of anaphase. Trends Cell. Biol. 8: 144-149.

Zhang, H., R. Kobayashi, K. Galaktionov, and D. Beach. 1995. p19Skp1 and p45Skp2 are essential elements of the cyclin A-CDK2 S phase kinase. Cell 82: 915-925. 


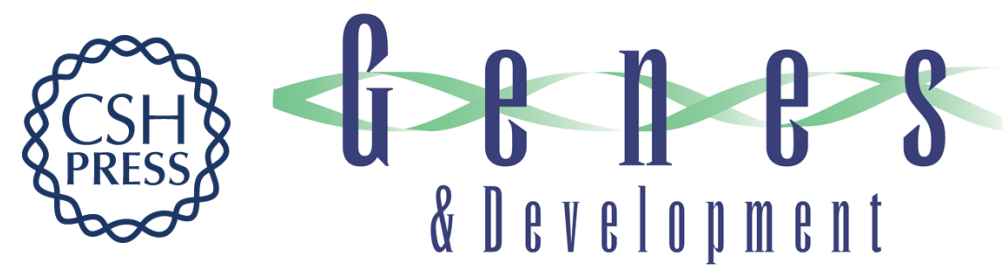

\section{Proper metaphase spindle length is determined by centromere proteins Mis12 and Mis6 required for faithful chromosome segregation}

Gohta Goshima, Shigeaki Saitoh and Mitsuhiro Yanagida

Genes Dev. 1999, 13:

References This article cites 66 articles, 30 of which can be accessed free at:

http://genesdev.cshlp.org/content/13/13/1664.full.html\#ref-list-1

License

Email Alerting

Receive free email alerts when new articles cite this article - sign up in the box at the top

Service

right corner of the article or click here.

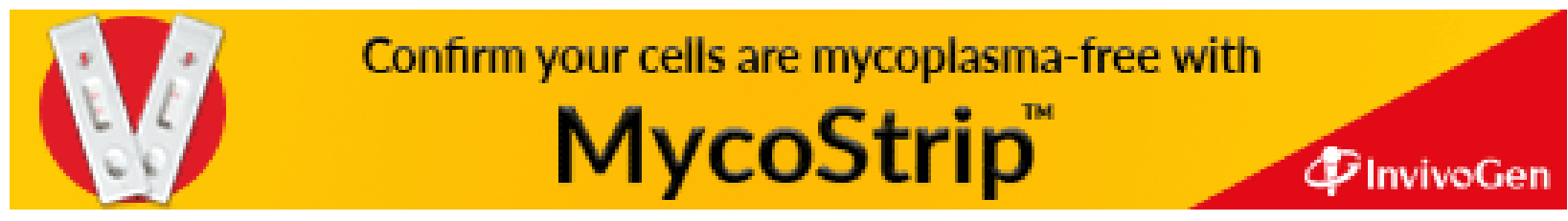

